\title{
Neurotic Factors of Self-Attitude Disorders in Adolescents
}

\author{
Denys Aleksandrov 1 [0000-0002-9307-2585], Ivan Okhrimenko ${ }^{2}$ [0000-0002-8813-5107], \\ Olena Tyshchenko 2 [0000-0003-4715-7235] \\ ${ }^{1}$ Taras Shevchenko National University of Kyiv, Kyiv, Ukraine \\ ${ }^{2}$ National Academy of Internal Affairs, Kyiv, Ukraine \\ *ivango-07@ukr.net
}

\begin{abstract}
The article analyses the relationship between different types of neurotic states with the functioning peculiarities of different components of the system of adolescent's self-attitude system. The most important factors of certain neurotic states, which are associated with disorders of adolescents' self-attitude system were determined, as well as subsequent mathematical and statistical processing and analysis of the leading correlation relationships were carried out on the basis of the conducted psychodiagnostic examination of 16-17 years old adolescents. In particular, anxiety is associated with an increased tendency to self-accusations, intrapersonal conflict, and decreased self-management. Depressive tendencies are associated with a tendency to unproductive self-accusations and the destruction of realised self-worth. Asthenic states are also associated with a tendency to self-accusations and low self-esteem. Hysteroid manifestations are also stipulated by a tendency to debilitating self-accusations, low self-worth, exacerbation of intrapersonal conflict, as well as fear of humiliation of one's image in the eyes of other people. Predisposition to phobic states is similarly associated with a decrease in self-worth both in one's own eyes and in the eyes of other people. Tendencies in autonomic disorders are also associated with a decrease in adolescents' awareness of their own worth. It can be concluded that preventive measures aimed at reducing the risks of neuroticism of adolescents should be aimed primarily at restoring their conscious self-worth.
\end{abstract}

Keywords: neurotic states, adolescents, self-attitude, individual and psychological qualities, self-worth.

\section{INTRODUCTION}

The problem of increasing stressors in modern society reflects adversely not only on the well-being and health of the entire population, but also has a negative impact on the psychological state of the most vulnerable category, which includes adolescents. Increased vulnerability of adolescents is also due to purely agespecific features inherent in the transition from childhood to adulthood. Adolescence is characterized by a desire for self-affirmation in new social roles and statuses, which cannot always be realized due to uncertainty in their real capabilities. In addition, the transition period is associated with a tendency to reevaluate one's self-image, which may conflict with social stereotypes that exist in adolescence and determine the criteria for the adolescent success among peers. More adaptive adolescents can direct their own efforts to accept their own real self-image in this process, or make efforts to self-improvement thus harmonizing their own process of moving into adulthood. In the case of violation of sociopsychological adaptation, the adolescent may focus on the experience of mismatch of his own real and expected idealized self-images, which creates personal dissonance, against which neurotic tendencies may arise, which, in turn, complicate adaptation processes.

Therefore, the aim of the article is to analyse the psychological aspects that determine the neurotic factors of self-attitude disorders in adolescents. This opens up prospects for improving the system of psychoprophylactic correctional aid, aimed at preventing the neurotization of adolescents by harmonizing the system of their attitude to their own self-image.

\section{LITERATURE REVIEW}

The problem of adolescent neurotic disorders has been considered by many scientists, both in the past and 
until quite recently. We would like to dwell on several important aspects of the problem of adolescents' neuroticism in modern conditions without going into an in-depth analysis of theoretical sources. Based on the conclusions of the longitudinal study of Huang C. [1], it is worth talking about the specifics of the formation of self-identification in the age of adolescence, which is characterized by dynamism due to the transformation of status-role images that adolescents learn as they move into adulthood.

Therefore it is necessary to begin the analysis from the point of view of natural socialization of the adolescent which results in harmonious development of the person. Thus, Malinowska-Cieślik M, Mazur J, Nałęcz H, Małkowska-Szkutnik A. [2] have shown on grounds of their own research that social conditions play the leading role in the process of harmonious development of adolescents, which are the basis for shaping adequate ideas about themselves and the outside world increasing their self-worth and reducing the risks of negative mental phenomena in general and neurotic manifestations in particular. Similarly, Viejo C., Gómez-López M., Ortega-Ruiz R. [3] emphasize that the basic prerequisite for the harmonious development of adolescents is their psychological well-being, which forms adequate self-perception reducing the risk of dissonance emergence due to dissatisfaction with their own system of self-attitudes.

Another perspective of the analysis of the causes of neurotic states emergence in adolescents is their selfesteem. And, as noted by Xin Yong, Li Qiongyao, Liu Chuanjun [4], adequate self-esteem is directly related to the social adaptation of adolescents. At the same time, self-esteem is determined by a set of stereotypes about the image of success existing within adolescent environment. Therefore, the harmony or disharmony of self-esteem is related to the external evaluation of the image of an adolescent by peers, through the prism of which he begins to overestimate his own image. Moreover, if he fails to accept himself as he is, he begins to compare himself with the external expectations of his social environment, trying to correlate his own real self-image with the idealized one of a successful image imposed by his peers. This can result in an exacerbation of the feeling of disharmony against the background of the dissonance of real and ideal self-images as well as the neurotization of personality.

There are two perspectives of understanding the problem in the context of the analysis of the role of selfesteem and self-attitude of the adolescent, as a prerequisite for his potential neuroticism. One perspective is due to self-esteem disorder in the direction of its overestimation, nevertheless Baumeister R. F., Campbell J. D., Krueger J. I., \& Vohs K. D. [5] emphasise that hypertrophied self- esteem with a corresponding tendency to demonstrative positioning of one's own successful image to other people can lead to violations of social interactions. In addition, such inflated self-esteem can be a sign of a protective neurotic reaction, which hides internal insecurity.

On the other hand, according to Ikiz F. E. \& Cakar F. S. [6], the presence of social support from the immediate environment contributes to the formation of adequate self-acceptance as an adolescent, despite the external images of success imposed by the adolescent environment. This makes the adolescent self-sufficient and harmonious.

Conversely, in case of lack of the immediate environment support, the adolescent does not form enough self-identification, resulting in a tendency to fall under the influence of externally imposed images, which often do not match the existing self-image resulting in self-dissatisfaction, dissonance, and as a consequence, neurotization. As noted by Lim Y. \& Lee O. [7], this problem is especially important not only in the situation of lack of support of the adolescent from the immediate environment, which is limited to pure deprivation, but is significantly exacerbated in the case of his abuse. The result of abuse is the destruction of the adolescents' perceptions of self-worth, reduced selfattitude and the emergence of neurotic defence mechanisms, which also complicate the process of their further social adaptation.

In addition, the adolescent's excessive susceptibility to externally imposed images that exist among his peers leads to the affectation of experiences. Such disorders of emotional response, as noted by Davis K. L., Panksepp J. \& Normansell L. [8], become a dangerous prerequisite for adolescent's neuroticism, in which case disorders can have a wide spectrum, ranging from purely psychological to neurological dysfunction.

It should be noted that cognitive dissonance [9] against the background of inconsistency of self-images causes a number of protective mechanisms, the distortion of which, according to Klein J., McColl G. [10], creates a disorder of self-identification, and, as a result, increases the risk of destructive mental formations. In this context, the conclusion made by Hagège J., Chammat M., Tandetnik C., Naccache L. [11] becomes naturally determined on the basis of their research concerning the inconsistency of one's own ideas about real and imagined idealized selfimage, which is the basis for the growth of cognitive dissonance. This is especially important in adolescents, whose age of transition is characterized by heightened self-perception, which may result in an increased risk of neuroticism. Moreover, the most stressful conditions of the modern world contribute to the development of neurotic formations in adolescents, especially in a situation of global shocks such as COVID-19 [12-14] 
epidemic, which, as noted by Aleksandrov D., Okhrimenko I. [15], hinder the normal process of socialization and adaptation of adolescents, which exposes them to the risk of neurotic states emergence.

At the same time, despite numerous studies, the analysis of the peculiarities of the emergence and the course of neurotic states in adolescents due to disorders of their self-attitude system, still remains an insufficiently disclosed topic, which induced our interest in this problem.

\section{METHODOLOGY}

The choice of psychodiagnostic method is stipulated by the need for a comprehensive research of psychological factors of adolescents' neuroticism in the context of disorders of the system of their self-attitude in order to implement the empirical research tasks. Taking into account the diversity of neurotic manifestations, the tools of empirical research included appropriate psychodiagnostic methods:

1) the Clinical Questionnaire for the detection and evaluation of neurotic states by K. K. Yakhin and D. M. Mendelevich. This method allows you to diagnose the following types of neurotic states: 1) anxiety, 2) neurotic depression, 3) asthenia, 4) hysterical reaction, 5) obsessive-phobic disorders, 6) autonomic disorders [16].

2) the method of the study of self-relationships (the attitudes towards oneself) "MSS" by S. R. Pantileev. This method was used to indicate the deformation of the adolescent's perceptions of their own "self-image", and contains the following scales aimed at the diagnostics of: 1) sincerity; 2) self-confidence; 3) self-control (selfmanagement); 4) demonstrated self-attitude; 5) selfworth; 6) self-acceptance; 7) self-affection; 8) intrapersonal conflict; 9) self-accusation [17].

The empirical basis of the research was made by 1852 15-17 years old adolescents, who underwent a routine examination in schools of Ukraine according to the method of K. K. Yakhin and D. M. Mendelevich in the course of their psychological follow-up in 20202021. Among them, the final sample included 212 adolescents who showed signs of neurotic states, in order to identify the peculiarities of the system of their self-attitude using the method of "MSS" by S. R. Pantileev. The research was conducted in 20202021, processing and interpretation of the results was conducted at the Department of Social Work of the Faculty of Psychology, Taras Shevchenko National University of Kyiv (Kyiv, Ukraine) and the Department of Legal Psychology of the National Academy of Internal Affairs (Kyiv, Ukraine).

Based on the tasks of the research, we carried out a mathematical and statistical analysis of the main correlation relationships of risk indicators of various neurotic disorders according to the method of K. K. Yakhin and D. M. Mendelevich with the indicators of individual psychological factors according to the method of S. R. Pantileev. In the course of processing, the existing relationships were determined by calculating Spearman's rank correlation coefficient. This is due to the fact that the metrics obtained are not subject to the law of normal distribution. It should be noted that concerning the sample size $(n=212)$, the statistical value of $r_{s}$ is not less than 0.139 with $p \leq 0.05$, the high value of $r_{s}$ is not less than 0.182 with $p \leq 0.01$, and the maximum value of $r_{s}$ is 0.231 with $p \leq 0.001$.

\section{Ethical considerations}

The research was approved by the Ethics Commission in accordance with the university community code of ethics, Taras Shevchenko National University of Kyiv. Informed consent was obtained from all participants; they were able to withdraw the study at any time.

\section{RESULTS}

We revealed the following peculiarities in the course of the analysis of correlation relationships of the indicators of neurotic states studied in adolescents using the method of the Clinical Questionnaire for the detection and evaluation of neurotic states (K. K. Yakhin, D. M. Mendelevich) with the indicators of the components of the self-attitude system according to the method of "MSS" by S. R. Pantileev (Table 1).

Anxiety is associated with an increase in the tendency to self-accusations $\left(r_{s}=0.530, p \leq 0.001\right)$. This can be explained by the fact that self-accusations reflect the inner dissatisfaction of the adolescent with himself. Moreover, this tendency may take the form of unproductive rejection of one's own image against the background of growing anxiety, which does not so much stimulate the adolescent to self-change as frustrate him. In addition, anxiety is associated with susceptibility to intrapersonal conflict $\left(r_{\mathrm{s}}=0.328\right.$, $\mathrm{p} \leq 0.001$ ), which corresponds to the above tendency to self-accusations. After all, the intrapersonal conflict demonstrates the dissonance between the real and the ideal self-image, dissatisfaction with which results in self-rejection of the adolescent, which becomes the background for the exacerbation of neurotic tendencies. Similarly, feelings of low self-worth are also associated with anxiety $\left(r_{s}=-0.280, p \leq 0.001\right)$, which may be explained by the adolescent's levelling of his or her current self-image due to underestimation and selfrejection. The exacerbation of such trends can be explained by age of adolescence, which is characterized by a focus on inflated expectations. Such adolescent maximalism makes the discrepancy between one's own expectations and the real self-image even more acute, which intensifies dissatisfaction and thus levels one's self-worth. In addition, there is some association 
between anxiety and decreased ability to selfmanagement $\left(r_{s}=-0.251, p \leq 0.001\right)$, which is a sign of the dominance of the external locus of control and a tendency to externality. This indicates that anxiety, which is so debilitating for the psyche and can lead to loss of self-control against the background of irritability due to the above-mentioned dissatisfaction with one's own current self-image. Constant internal tension stipulates psychasthenic tendencies, the result of which is a decrease in self-control and a tendency to situational impulsive loss of self-management. It is worth noting that the identified trends have two-way connections, as a result of which internal dissatisfaction generates anxiety, and growing anxiety, in turn, provokes an even greater dissonance between the real and the expected ideal self-image.

Table 1. Correlation relationships of neurotic states with the components of adolescents' self-attitude system

\begin{tabular}{|l|c|c|c|c|c|c|}
\hline $\begin{array}{c}\text { Components of } \\
\text { adolescents' self- } \\
\text { attitude system }\end{array}$ & Anxiety & $\begin{array}{c}\text { Neurotic } \\
\text { depression }\end{array}$ & Asthenia & $\begin{array}{c}\text { Hysterical } \\
\text { reaction }\end{array}$ & $\begin{array}{c}\text { Obsessive } \\
\text { phobias }\end{array}$ & $\begin{array}{c}\text { Autonomic } \\
\text { disorders }\end{array}$ \\
\hline Unsociability & 0.048 & -0.039 & 0.029 & -0.032 & -0.033 & -0.009 \\
\hline Assertiveness & 0.030 & -0.028 & 0.119 & 0.017 & 0.064 & -0.137 \\
\hline Internality & -0.251 & -0.112 & -0.041 & 0.012 & -0.008 & 0.117 \\
\hline $\begin{array}{l}\text { Agreeableness of } \\
\text { wider public }\end{array}$ & -0.212 & -0.165 & -0.100 & -0.244 & -0.352 & 0.080 \\
\hline Self-worth & -0.280 & -0.395 & -0.315 & -0.407 & -0.282 & -0.245 \\
\hline Self-acceptance & 0.094 & 0.100 & 0.129 & -0.048 & 0.036 & 0.195 \\
\hline Self-affection & -0.026 & -0.178 & -0.042 & -0.069 & -0.019 & -0.146 \\
\hline Internal conflict & 0.328 & 0.241 & 0.118 & 0.294 & 0.156 & -0.021 \\
\hline Self-accusation & 0.530 & 0.482 & 0.319 & 0.465 & 0.227 & 0.197 \\
\hline
\end{tabular}

Adolescents' predisposition to neurotic depressive reactions was the next neurotic state we correlated. Two main relationships were found in in terms of correlation with the system of self-attitude of adolescents. Thus, depressive tendencies are associated with a tendency to unproductive self-accusations $\left(\mathrm{r}_{\mathrm{s}}=0.482, \mathrm{p} \leq 0.001\right)$. This can be explained by the fact that the unwillingness to accept oneself as he or she is provokes the adolescent not to try to make efforts for self-improvement in order to bring the real self-image closer to the desired ideal, but to unproductive self-accusations of failure. Depressive tendencies become especially acute due to the tendency of adolescents to compare themselves with peers who seem more successful, as well as through attempts to compare themselves with idealized images of social stereotypes of success that exist within adolescent environment. This corresponds to the next significant correlation of the indicator of depressive reactions with the destruction of conscious self-worth $\left(r_{s}=-0.395, p \leq 0.001\right)$, which can also be explained by the levelling of one's own real self-image, which does not correspond to the adolescent's idea of idealized selfimage formed due to the focus on social stereotypes of the image of success that exist within adolescent environment. Let us note that, as in the situation with the anxiety described above, depressive tendencies also have a two-way relationship with self-accusations and levelled self-worth, which, on the one hand, exacerbate depressive experiences, and on the other - grow with the increase of depressive manifestations.

In turn, the vulnerability to asthenic states of adolescents has similar relationships with the tendency to obsessive self-accusations $\left(r_{\mathrm{s}}=0.319, \mathrm{p} \leq 0.001\right)$, which confirms our above assumption about the debilitating nature of anxiety, which arise against the background of rejection of self-image by adolescents because of their apparent imperfection. Similarly, the correlation with the manifestation of contempt for selfworth $\left(\mathrm{r}_{\mathrm{s}}=-0.315, \mathrm{p} \leq 0.001\right)$ is explained by the debilitating nature of the inner experiences of dissonance between the real and the desired idealized self-image.

Adolescents' hysteroid manifestations are often interdependent with a tendency to debilitating selfaccusations $\quad\left(r_{s}=0.465\right)$, which indicates the compensatory nature of hysterical demonstrations due to internal dissatisfaction. This corresponds to the above tendency to impulsive discharges of accumulated mental tension in the form of situational loss of self-control. In turn, this is confirmed by a corresponding decrease in realised self-worth $\left(\mathrm{r}_{\mathrm{s}}=-0.407, \mathrm{p} \leq 0.001\right)$, which can generate in the adolescent compensatory desire for demonstrative behaviour in order to attract attention from other people. Due to this, there is an increase in intrapersonal conflict $\left(r_{s}=0.294, p \leq 0.001\right)$, which can also exacerbate hysteroid reactions due to the desire to hide the internal dissonance between the existing and the ideal self-image from other people. As a result of the accumulation of such internal tension due to dissatisfaction with one's self-image, there is a fear of humiliation of one's image in the eyes of other people $\left(r_{s}=-0.244, p \leq 0.001\right)$, which pushes the adolescent to demonstrative behaviour, such as an actualization of the desire to attract attention and gain the support of other people at any cost. 
Predisposition to phobic obsessive states in adolescents is largely associated with a decrease in realised self-worth ( $\mathrm{rs}=-0.282, \mathrm{p} \leq 0.001$ ), which can be explained by an increase in fear of losing their own face both in their own eyes and in the eyes of the reference environment of peers who seem more successful to the adolescent. Another correlation relationship is natural, which may confirm our assumption that phobic manifestations are associated with perceptions of one's own image in the eyes of other people $\left(\mathrm{r}_{\mathrm{s}}=-0.352, \mathrm{p} \leq 0.001\right)$. The adolescent projects his own dissatisfaction on others and expects the same dissatisfaction, condemnation, or even humiliation from peers. Thus, the obsessive fears of the adolescent are stipulated by the perceived threat of the destruction of the attractiveness of the self-image, both in his or her own eyes and in the eyes of the reference environment.
As for the predisposition to autonomic disorders as a form of neurotic reactions, it showed the only significant relationship with the indicator of tendency to decline in adolescents' awareness of their self-worth $\left(r_{s}=-0.245, p \leq 0.001\right)$, which can be explained by the tendency to hypertrophied reassessment of their physiological components in the age of adolescence, which undergo natural changes during puberty. In addition, this relationship can be explained by a certain tendency to somatize the above anxiety and phobic reactions, as one of the unproductive defence mechanisms inherent in neurotic states.

It is also worth mentioning the presence of regular relationships between the indicators of neurotic states of the adolescents of interest (Table 2).

Table 2. Correlation relationships of the main forms of neurotic disorders

\begin{tabular}{|c|c|c|c|c|c|c|}
\hline & Anxiety & $\begin{array}{c}\text { Neurotic } \\
\text { depression }\end{array}$ & Asthenia & $\begin{array}{c}\text { Hysterical } \\
\text { reaction }\end{array}$ & $\begin{array}{c}\text { Obsessive } \\
\text { phobias }\end{array}$ & $\begin{array}{c}\text { Autonomic } \\
\text { disorders }\end{array}$ \\
\hline Anxiety & & 0.747 & 0.610 & 0.519 & 0.402 & 0.283 \\
\hline Neurotic depression & 0.747 & & 0.788 & 0.592 & 0.551 & 0.425 \\
\hline Asthenia & 0.610 & 0.788 & & 0.468 & 0.311 & 0.382 \\
\hline Hysterical reaction & 0.519 & 0.592 & 0.468 & & 0.491 & 0.450 \\
\hline Obsessive phobias & 0.402 & 0.551 & 0.311 & 0.491 & & 0.155 \\
\hline Autonomic disorders & 0.283 & 0.425 & 0.382 & 0.450 & 0.155 & \\
\hline
\end{tabular}

Thus, depression is most associated through significant correlation relationships with debilitating asthenia $\left(r_{s}=0.788, p \leq 0.001\right)$, anxiety $\quad\left(r_{s}=0.747\right.$, $\mathrm{p} \leq 0.001)$, hysteroidal reactions $\left(\mathrm{r}_{\mathrm{s}}=0.592, \mathrm{p} \leq 0.001\right)$ and phobic tendencies $\left(\mathrm{r}_{\mathrm{s}}=0.551, \mathrm{p} \leq 0.001\right)$. In turn, anxiety is associated with depression $\left(r_{s}=0.747\right.$, $\mathrm{p} \leq 0.001)$, asthenization $\left(\mathrm{r}_{\mathrm{s}}=0.610, \mathrm{p} \leq 0.001\right)$ and hysteroidism $\quad\left(\mathrm{r}_{\mathrm{s}}=0.519, \quad \mathrm{p} \leq 0.001\right)$. Debilitating asthenia has significant associations with depression ( $r s=0.788)$ and anxiety $\left(r_{s}=0.610\right)$. In addition, the predisposition to demonstrative histerical reactions is primarily associated with neurotic depression $\left(r_{s}=0.592, \quad p \leq 0.001\right) \quad$ and anxiety $\quad\left(r_{s}=0.519\right.$, $\mathrm{p} \leq 0.001)$.

Other neurotic states have fewer significant correlation relationships, so we will not consider them. But, given the number of strong weighty correlation relationships with all other forms of neurotic states, it can be argued that exactly neurotic disorders of the anxiety circle are most inherent in this category of the studied contingent, which can be explained by age characteristics such as uncertainty in the success of one's own image in one's own eyes and the eyes of peers arising due to fear of the impossibility of selfaffirmation, as well as due to personal dissonance against the background of the discrepancy between the real and the idealized self-image, due to stereotypes of the age of adolescence.

\section{CONCLUSIONS}

The research showed that adolescents' susceptibility to neurotic states is most associated with decreased selfworth. After all, we revealed the inverse significant correlation relationships of all neurotic disorders with this personalized peculiarity of the self-attitude system. The second most important peculiarity of the adolescent's self-attitude system against the background of neuroticism is the propensity for unproductive selfaccusations, as evidenced by four of the six possible significant correlation relationships. In addition, a certain influence in the formation of neurotic states of adolescents is caused by exacerbated age-related intrapersonal conflict and fear of underestimation of adolescents by other people, which can be explained by fear of not being attractive and successful in their own eyes and in the eyes of peers especially against the background of dissatisfaction with their own real selfimage, which does not coincide with the idealized image of success imposed by social stereotypes existing within adolescent environment. This is confirmed by the fact that both structures of the system of self-attitude have two important correlation relationships with the studied forms of neurotic manifestations. It was also revealed 
that exactly neurotic disorders of the anxiety circle are most inherent in adolescents, which can be interpreted due to the peculiarities of the age of transition, which is often characterized by insecurity in the success of one's own image arising due to personal dissonance against the background of the discrepancy between the real and the idealized self-image. Thus, the improvement of the system of psychoprophylactic correctional aid should be aimed at preventing the neurotization of adolescents by harmonizing the system of their attitude to their own self-image.

\section{REFERENCES}

[1] Huang, C. (2010), "Mean-level change in selfesteem from childhood through adulthood: Meta-analysis of longitudinal studies", Review of General Psychology, vol. 14, pp. 251-260, available at: https://doi.org/fdp4pb

[2] Malinowska-Cieślik, M. Mazur, J. Nałęcz, H. and Małkowska-Szkutnik, A. (2019), "Social and Behavioral Predictors of Adolescents' Positive Attitude towards Life and Self", International Journal of Environmental Research and Public Health, vol. 16 (22), 4404. DOI: 10.3390/ijerph16224404

[3] Viejo, C. Gómez-López, M. and Ortega-Ruiz, R. (2018), “Adolescents' psychological well-being: A multidimensional measure", International Journal of Environmental Research and Public Health, vol. 15, $2325 . \quad$ DOI: 10.3390/ijerph15102325

[4] Xin Yong, Li Qiongyao and Liu Chuanjun (2019), "Adolescent Self-esteem and Social Adaptation: Chain Mediation of Peer Trust and Perceived Social Support", Social Behavior and Personality: an international journal, vol. 47 (4), pp. 1-9. DOI: 10.2224/sbp.7870

[5] Baumeister, R.F. Campbell, J.D. Krueger, J.I. and Vohs, K.D. (2003), "Does high self-esteem cause better performance, interpersonal success, happiness, or healthier lifestyles?", Psychological Science in the Public Interest, vol. 4, pp. 1-44, available at: https://doi.org/bzdjwj

[6] Ikiz, F.E. and Cakar, F.S. (2010), "Perceived social support and self-esteem in adolescence", Procedia-Social and Behavioral Sciences, vol. 5, pp. 2338-2342, available at: https://doi.org/bm6gbf

[7] Lim, Y. and Lee, O. (2017), "Relationships between parental maltreatment and adolescents' school adjustment: Mediating roles of self-esteem and peer attachment", Journal of Child \& Family
Acknowledgements. There are no acknowledgements.

Funding. There was no outside funding provided for this study.

Disclosure statement. No author has any financial interest or received any financial benefit from this research.

Conflict of Interest. The authors declare that there are no conflicts of interest.

Studies, vol. 26, pp. 393-404, available at: https://doi.org/f9q64f

[8] Davis, K.L. Panksepp, J. and Normansell, L. (2014), "The affective neuroscience personality scales: Normative data and implications", Neuropsychoanalysis, vol. 5 (1), pp. 57-69. DOI: 10.1080/15294145.2003.10773410

[9] Ilana, Lavy and Rashkovits, Rami (2018), "The Circumstances in which Modular Programming becomes the Favor Choice by Novice Programmers", International Journal of Modern Education and Computer Science (IJMECS), vol. 10, no. 7, pp. 1-12. DOI: 10.5815/ijmecs.2018.07.01

[10] Klein, J. and McColl, G. (2019), "Cognitive dissonance: how self-protective distortions can undermine clinical judgement", Medical Education, DEC; vol. 53 (12), pp. 1178-1186. DOI: $10.1111 /$ medu. 13938

[11] Hagège, J. Chammat, M. Tandetnik, C. and Naccache, L. (2018), "Suggestion of self(in)coherence modulates cognitive dissonance", PLoS One, Aug 30; vol. 13 (8), e0202204. DOI: 10.1371/journal.pone.0202204.

[12] Anurag, Tatkare Hemangi, Patil Tejal, Salunke Shreya, Warang and Dipak, Marathe (2021), "COVID-19 Patient Health Monitoring System", IJEM, vol. 11, no. 5, pp. 48-55. DOI: $10.5815 /$ ijem.2021.05.05

[13] Ahmed Hassan Mohammed Hassan, Arfan Ali Mohammed Qasem, Walaa Faisal Mohammed Abdalla and Omer H. Elhassan (2021), "Visualization \& Prediction of COVID-19 Future Outbreak by Using Machine Learning", IJITCS, vol. 13, no. 3, pp.16-32. DOI: $10.5815 /$ ijitcs.2021.03.02

[14] Mirza Waseem Hussain, Tabasum Mirza, Malik Mubasher Hassan (2020), "Impact of COVID-19 Pandemic on the Human Behavior", IJEME, vol. 10, no. 5, pp. 35-61. DOI: $10.5815 /$ ijeme.2020.05.05 
[15] Aleksandrov, D. Okhrimenko, I. (2020), "Psychological Risk Factors of the Neurotization of Adolescents under the Conditions of Quarantine Measures of the COVID-19 Epidemic", Broad Research in Artificial Intelligence and Neuroscience, vol. 11 (2Sup1), pp. 29-36. DOI: 10.18662/brain/11.2Sup1/91
[16] Mendelevich, D.M. (2016), Psihologiya deviantnogo povedeniya [The Psychology of Deviant Behavior], Gorodec, Moskva, Rossiia.

[17] Pantileev, S.R. (1993), Metodika issledovaniya samootnosheniya [Self-Relationship Research Methodology], Smy`sl, Moskva, Rossiia. 